\title{
Economic-behavioral Analysis of Delinquent Acts Based on the Report of Juvenile Offenders in Confinement
}

\author{
Ariela Oliveira Holanda ${ }^{1, *}$ (D) \& Jorge Oliveira-Castro ${ }^{2}$ (D) \\ ${ }^{1}$ Instituto Federal do Paraná, Londrina, PR, Brasil \\ ${ }^{2}$ Universidade de Brasília, Brasília (UnB), DF, Brasil
}

\begin{abstract}
From a behavioral-economic approach of delinquent behavior, this research aimed to identify potential consequences that could alter the cost of crime from the offender's perspective. A questionnaire prepared to assess the level of informational and utilitarian reinforcement and punishment of these consequences was answered by 118 juvenile offenders in confinement. The reported level of informational reinforcement did not predict the level of multiplicity of offenses committed. The reported levels of utilitarian reinforcement, informational punishment, and utilitarian punishment predicted this level of multiplicity. Only the level of utilitarian punishment decreased the likelihood of an offender having been involved in more types of criminal acts. Theoretical and practical implications of these findings are discussed.
\end{abstract}

KEYWORDS: behavioral economics, delinquent behavior, behavioral perspective model

\section{Análise Econômico-Comportamental de Atos Infracionais com Base no Relato de Jovens Privados de Liberdade}

\begin{abstract}
RESUMO - A partir de uma interpretação econômico-comportamental do comportamento delinquente, este estudo buscou identificar potenciais consequências capazes de alterar o custo do crime do ponto de vista do próprio infrator. Um questionário elaborado para a avaliação do nível de reforçamento e punição, informativo e utilitário, dessas consequências foi aplicado a 118 jovens em privação de liberdade. O relato do nível de reforçamento informativo não predisse o nível de multiplicidade dos atos infracionais praticados. Já os relatos dos níveis de reforçamento utilitário e de punição informativa e utilitária predisseram a multiplicidade. Apenas a punição utilitária diminuiu a chance de o infrator ter se envolvido em mais tipos de atos. Implicações teóricas e práticas desses achados são discutidas.
\end{abstract}

PALAVRAS-CHAVE: economia comportamental, comportamento delinquente, behavioral perspective model

The phenomena related to juvenile delinquency are a long-lasting challenge to public policy makers and managers. These are complex phenomena that bear double and ambiguous burden of victimization as they entail risks to the ordinary citizens' lives, victims of delinquent acts, while making the juvenile offenders victims with reduced chance of building a harmonious life in society.

That ambiguity is reflected in the theories and studies aimed to understand and predict juvenile delinquency.
Several developmental theories intend to describe the processes of acquisition and maintenance of the delinquent behavior (cf. Gaik, Abdullah, Elias, \& Uli, 2010). These theories range from those pointing out psychopathy and low self-control as predecessors of that behavior, i.e., that attribute the causes of a behavior to an individual's own characteristics, to those that perceive delinquency as a response to the environment in which the individuals are inserted, i.e., theories that emphasize environmental and

\footnotetext{
Apoio: Capes

* Email: ariela.holanda@gmail.com

- Submetido: 08/09/2016; Revisado: 25/10/2016; Aceito: 09/08/2017.
} 
situational causes (cf. Nijhof, de Kemp, \& Engels, 2009). The theoretical framework about delinquent behavior also includes other promising theoretical trends grounded on theories quite different from the developmental theories, or those of psychopathologic nature. This is true for economy. In the light of concepts and ideas originated in economy, Becker (1993) proposed an economic approach to handle behavioral issues of social relevance such as discrimination of minorities; the formation, dissolution and structure of families; and the one comprising the focus of analysis of this study: crime and punishment.

Generally, as Becker (1993) explains, his approach is a method of analysis rather than a set of assumptions about specific motivations. His analysis assumes that while behaving, individuals maximize not only the financial gain, but also their well-being, in their individual perspective, regardless if they are selfish, altruist, loyal or masochist. The author affirms that behaviors occur within several resources restriction, such as income, time, memory failure, economic opportunities, among others. These opportunities largely differ from person to person, as they depend on individual and collective actions of other individuals or organizations. However, there is a restriction common to everyone: time limitation. The day has 24 hours for everyone. The way each individual deal with these restrictions defines their behavior.

Specifically concerned about crime and punishment, based on the idea that apparently the crime merely redistributes resources, Becker (1968) proposed that the cost of punishment to the offender should be considered in the estimate of the social loss caused by the crime. If punishment is a fine, for example, the cost to the offender is the amount of the fine. If, on the other hand, punishment is a period of deprivation from freedom, the cost to the offender can be estimated by multiplying their average daily earning in freedom by the number of days in confinement. The gain resulting from delinquent behavior is not limited to financial gains, however. Therefore, estimating the cost of punishment to offenders also involves assessing the consequences of the delinquent behavior to the offender, and the degree of influence of such consequences on the delinquent behavior. Understanding delinquent behavior in the light of a theoretical model that grants to environmental variables a core role in the maintenance of such behavior, and that integrates, in a theoretically consistent way, known predictive variables, could be very useful.

\section{BEHAVIORAL PERSPECTIVE MODEL APPLIED TO DELINQUENT BEHAVIOR}

Inspired by Skinner's model of 3-term contingency (Skinner, 1953), Foxall (1998) proposed a model based on the behavioral perspective (Behavioral Perspective Model - BPM) to study the consumer's behavior. According to the model, the consumption behavior is influenced by the current situation, and includes the scenario variables and the consumer's learning history. Four types of elements or discriminative stimuli make up the current context of consumption behavior: physical (e.g., advertisements, logos, and showcases); social (e.g., number of sellers and consumer's companions); temporal (e.g., season, commemorative dates, and duration of offers) and normative (e.g., specific norms of conduct of a store or established by the consumer).

These antecedent stimuli point out the likelihood of four types of consequences: utilitarian reinforcement; informational reinforcement; utilitarian punishment; and, informational punishment (Foxall, 1998, 2010). The utilitarian consequences directly derive from the use and possession of a given product or service. The door-to-door transport resulting from the purchase and use of a car is an example of utilitarian reinforcement. The money spent to acquire that car that hinders access to other reinforcements also produced with money, in turn, is an example of utilitarian punishment. The informational consequences are symbolic, as these are mediated by the action of others, and refer to the level of social status, prestige and acceptance or rejection obtained by the consumer through the purchase and use of a given product or service. The social status assigned to someone who buys a luxury car is an example of informational reinforcement. The derogatory comments of colleagues regarding the purchase of an economy car, on the other hand, are an example of informational punishment.

Although being originally proposed to study the consumer's behavior, in the behavioral perspective, the model can be used to explain other types of behavior. Understanding the delinquent behavior in the BPM light is to remove it from the field of private motivations conceived as causes of the behavior, and get it closer to the economic perspective proposed by Becker (1993).

Little is known about the informational and utilitarian levels of delinquent behavior's consequences. Joining crime may produce common consequences to all offenders. The permanent risk of being arrested, for example, is shared by all offenders, and the involvement with peer groups may work as motivation to remain in crime (e.g., Asscher, Wissink, Deković, Prinzie, \& Stams, 2014). Specifically regarding the youth, feelings arising from the involvement with crime may have a more effective motivating role during adolescence than in adulthood (Southamer-Loeber \& Loeber, 1988). That means to say that the feelings resulting from crime may play a reinforcing role to the delinquent behavior at large, mainly during adolescence. 
On the other hand, some crimes tend to produce specific consequences. Theft and robbery, for example, produce access to the good stolen or robbed, while a homicide may produce the elimination of a threat. Both consequences produce access to both informational and utilitarian reinforcement and punishment. Showing things of value, for example, could indicate the power of a drug dealer (cf. Boles \& Miotto, 2003), or pinpoint them as a threat to the others in the fight for market. The elimination of threats, in turn, could result in the acquisition of social prestige among the delinquent peers, or the detachment of neighbors and friends that fear being also victims of homicides.

Considering the delinquent behavior conceived by Becker (1993) as a behavior that, like any other, maximizes the resources considered important by the individual, this study aims to investigate, in the BMP light, what types of variables could be maximized by delinquent behaviors.
Considering that each type of crime tends to produce specific consequences, this study tried to evaluate if such consequences tend to change the likelihood of committing different types of crime. The overall aim is to investigate the potential consequences, regardless if reinforcements or punishments, if utilitarian or informational, produced by the delinquent behavior and predict, based on the reinforcement and punishment value of these consequences, based on the report by the offenders, the different types of crime committed by adolescents and young adults. Specific objectives are: (a) design a tool that allows the assessment of reinforcement and punishment value, informational or utilitarian, of potential consequences of the delinquent behavior; (b) cluster young delinquents according to the number of different types of crime committed; and, (c) identify the most likely crimes in each group.

\section{METHOD}

\section{Participants}

This study comprised 118 male adolescents and young adults serving socio-educational confinement measures in one of two public institutions in a state in the Northeast region of Brazil. One of the institutions was for adolescents of 16 to 17 years old and the other for young adults of 18 to 21 years old. The participants' age ranged from 17 to 20 years $(M=17.68 ; S D=0.78)$.

\section{Setting and Materials}

An iPad Apple MD371LL/A $3^{\text {rd }}$ generation and a tablet Samsung Galaxy Note 10.1 GT-N8013EAVXAR were used to collect data. Data were collected in rooms made available by the institutions in which participants were confined. Rooms were furnished with table, chairs, bulletin boards, computers and cabinets to keep the files of the inmates. During data collection the rooms were unavailable for meetings and attendance by the employees of the institutions.

\section{Instrument}

Data collection employed a questionnaire designed to assess the level of informational and utilitarian reinforcement and punishment of potential consequences of the delinquent behavior. The term potential indicates that maybe the consequences assessed were not actually experienced by the participants when committing crimes. However, the consequences were pointed out either by the field literature, or by the offenders, or by the employees of the detention institutions that housed the participants, as potential consequences of delinquent behavior. The questionnaire comprised 71 items, each one corresponding to an affirmation in the third singular person that should be assessed in a 5-point scale (1-strongly disagree, 2 -disagree, 3 - neither agree nor disagree, 4 - agree and 5 - strongly agree).

The potential consequences of the delinquent behavior analyzed were: access to firearm (5 items); access to illegal drugs (5 items); access to clothing and accessories (4 items); making friendship (4 items); making enemies (4 items); immediate consequences of crime ([e.g., elimination of threats, obtainment goods, feelings of pleasure]; 6 items); permanent state of stress ( 6 items); involvement with gangs ( 8 items); police escape (5 items); dangerousness (4 items); deprivation from freedom (10 items); provision of goods and services to the community (4 items); and provision of goods and services to the family ( 6 items). The questionnaire items tried to evaluate the informational and utilitarian dimensions of each consequence. Considering that reinforcements and punishments can be provided by different sources such as, e.g., the society at large, groups of peers, or family members, the statements allowed participants to assess the possible effects of the consequences described on different contexts in which they could take place. Because of that, the questionnaire used was made up by statements of different degrees of coverage, i.e., from those trying to evaluate the informational and utilitarian values of reinforcements and punishments assigned to the potential consequences generated exclusively by the criminal behavior, typically provided by the society, to those aimed at the evaluation of reinforcements and punishments provided by the offender 
peers or, in general, the social scenarios experienced by the offenders, even if not exclusively produced by the acts. Therefore, some consequences included in the questionnaire are more exclusively associated to crimes than others, that could be less associated to such acts. Following are some examples of the questionnaire items: "The person that helps family members, giving them things, is cherished in the family"; "It is important to have firearms for protection", "A person with many enemies is viewed with suspicion by the community members" and "Who is arrested is abused". The first example illustrates a generic consequence, not exclusively generated by crimes, but that could be a consequence of delinquent acts (e.g., steal or rob to support the family). The last example about consequences associated to prison, in turn, shows a consequence typically produced almost exclusively by crimes.

The questionnaire also included a question about the participant's age and another about which crimes he had committed. The answers to this last question were: theft, robbery, homicide, attempted homicide, armed robbery, illegal firearm carrying, bodily injury, drug dealing, rape, criminal conspiracy, and others. This last option asked the participant to describe which other acts he had practiced.

\section{Procedure}

Procedure was 3-stage: (a) instrument design; (b) data collection; and (c) data analysis. Each stage is described below.

Instrument design. The consequences of the delinquent behavior assessed by the instrument used to collect data were selected based on three sources: (a) previous literature; (b) informal chat with employees of the institutions where data were collected; and, (c) semi-structured interviews (cf. Minayo, 2009, p. 64) with confined youngsters and adolescents. Obtaining information from the last two sources met a double objective. In addition to surveying potential reinforcements and punishments of the specific delinquent behavior of the sample to be analyzed, it allowed the early contacts with the institutions and inmates, and getting familiar with the institutional routine and possibilities of carrying out the survey.

Informal chats were carried out with the technical staff of the institutions (attorneys, nurses, dentists, psychologists, and social assistances), with directors and educational trainers (employees in charge of monitoring the inmates routine in the institutions), whenever they were available. Interviews were made with three inmates that accepted being interviewed anonymously. The interviews followed a script that included statements that started histories to be completed by the respondents. Some of the statements used were: "Luis was a famous offender respected by all because...", "The family perceived Luis as..." and "Carlos was also an offender and also said that the downside of criminal life was..." During interviews the respondent was frequently asked to talk more about the consequences of the delinquent behavior they had pointed out.

After gathering the potential consequences of the delinquent behavior, at least four statements were designed to each consequence: two involving their reinforcement dimensions, of which one referred to the informational level of reinforcement and the other to the utilitarian level; and two involving the punishment dimensions, which were also assessed at the informational and utilitarian levels. To verify the responsiveness of the statements elaborated to the proposal of assessing the informational and utilitarian value of the consequences described, the items were subjected to judge analysis (cf. Pasquali, 1998). Two judges with broad knowledge about BPM were selected, both who authored Master's thesis where the model was adopted. Each judge received a table with the questionnaire items, presented in alphabetical order on the lines, and with columns stating the following titles: informational reinforcement; utilitarian reinforcement; informational punishment; and, utilitarian punishment. Judges should mark which title was being assessed by each item. Tables were individually completed, with no communication between the judges. The judges' assessments were compared one another, and with the table initially prepared to design the questionnaire that indicated which title each item was intended to measure. Eleven items with at least one point of disagreement in any of the comparisons were reworded. Items were organized in a sequence starting from the most generic to the most sensitive, i.e., most personal (cf. Günther, 2003). Three volunteers, with complete higher education, were asked to evaluate how sensitive each item was, using a 1 to 5 scale where 5 would indicate the most sensitive items. The mean of the three evaluations was calculated and items were organized in ascending order.

Data collection. Data collection lasted for one month, from February to March 2014. Two interviewers, with university degree in Psychology and previous experience of care to adolescents in conflict with the law in the socioeducational system, carried out the individual interviews.

Before starting the interview sessions, the Informed Consent Form (ICF) was presented to the directors of the respective institutions, considered to be legally responsible for the inmates. When the directors approved and signed the ICF, interviews started. Before the interview, the ICF was read out loud and explained to the respondent, who had their doubts clarified, and decided about their participation in the survey. Those who accepted to participate were asked to sign the Form.

Data were collected using the application QuickTapSurvey (Version 5.5.1), developed to construct questionnaires and collect data. The use of the application allowed introducing the whole instrument to the respondents on electronic devices with touch screen. The sequence of screens is 
described below. The logo of the University of Brasilia was displayed on the left upper corner of each screen. A horizontal bar was displayed on the bottom part of the screens. The bar was filled in green as the session advanced, so that by the end of the interview the bar was totally filled. On the right side of that bar, there were two keys with arrows to the right and to the left, respectively used to move to the next screen, and return to the previous screen. The right arrow remained inoperative until the respondent did what was requested. This ensured the inexistence of absent values in the database.

After signing the ICF, the screen named what is your opinion? was displayed to the participant. The screen contained the initial instructions that described the task to be performed. When the interviewer read the instructions, the respondent should clarify his doubts about the task to be formed and touch the test key. This led to the display of a new screen with a test item. The screen of that item reproduced the following screens on which each item of the tool would be displayed. The item of test corresponded to the following statement: "Playing football is good". The respondent should give his opinion about to which extent he agreed with the item presented by sliding, with the finger, a cursor on a horizontal bar. Under the bar, on the left corner, was displayed Strongly disagree and on the right corner Strongly agree. As the respondent slipped the cursor on the bar, a field under the item presented and above the bar displayed the option corresponding to the cursor position in relation to the bar. When the cursor was slipped to the left side of the bar, the field presented the option Strongly disagree. When the cursor was moved a little to the right, the next option displayed was Disagree, followed by Neither agree nor disagree with the cursor on the middle of bar, Agree with the cursor more to the right, and Strongly agree with the cursor on the right end of the bar. When the option corresponding to the respondent's option was displayed, he should touch the key with the arrow to right, which would display the next screen.

When the test was completed, the screen named understood? was displayed. This screen contained the three following questions: "Did you understand how the survey will work?", "Do you have any doubt?" and "Let's start?" When doubts were clarified the respondent should touch the key start. Then, a sequence of 71 screens was presented. Each screen had an item of the questionnaire, and the respondent should do as he did during the test.

After all items had been presented, the screen named to conclude was displayed, showing the following statement: "To complete the survey, I would like to ask two pieces of information about you". Touch the key next, the next screen asked the respondent to type his age using the numerical keyboard on the screen. The next screen asked the respondent to inform which crimes he had already committed. The screen presented several options of crimes. The respondent should touch on those describing crimes he had already committed. The option others, when selected, directed the respondent to a screen with alphanumerical keyboard, so he could write which other crimes, additionally to those presented in the options, he had committed. The last screen displayed thanked the respondent for his participation.

The interviewers read out loud the content of each screen to the respondent. This allowed interviewing inmates that could not or could hardly read. In these events, when the respondents selected the position of the cursor on the horizontal bar to respond to which extent they agreed with the items displayed, the interviewer read the selected option to the respondent. If the respondent disagreed with the option, he should move the cursor until the field destined to present the selected option displayed the option he wanted. For questions requesting typing, the interviewers typed the answers of the respondents who requested so. When typing was concluded, the interviewer read the answer to the respondent. All participants could sign the form, and obtaining fingerprint was not required.

Data analysis. Three types of analyses were performed: (a) cluster analysis; (b) chi-square tests; and, (c) logistic regression analyses. The first aimed at pooling data for further analyses. Participants were distributed in clusters of different levels of multiplicity of crimes committed. The second analysis aimed at validating the clusters solution obtained, and identifying which types of crimes were more likely in each group. The third analyses tried to assess the predictive value of each type of reinforcement and punishment in relation to the likelihood of belonging to the clusters formed.

A discrete quantitative variable, named multiplicity of crimes committed, was created to the cluster analyses. One point was added to the variable for each of the following crimes committed: (a) bodily injury (cf. Decree 2,848/1940, art. 129); (b) homicide (cf. Decree 2,848/1940, art. 121) and/or attempted homicide; (c) receiving stolen property/ goods (cf. Decree 2,848/1940, art. 180); (d) theft (cf. Decree 2,848/1940, art. 155); (e) robbery (cf. Decree 2,848/1940, art. 157); (f) armed robbery (cf. Decree 2,848/1940, art. 121) and/or attempted armed robbery; (g) drugs dealing (cf. Law 11,343/2006, art. 33). (h) illegal firearm carrying (cf. Law 10,826/2003, arts. 14 and 16); and (i) criminal conspiracy (cf. Decree 2,848/1940, art. 289). The crime of rape (cf. Decree 2,848/1940, art. 123) was not self-reported by any respondent. The calculation of this variable disregarded crimes reported in the option others by no more than two participants.

Cluster analyses were performed in two stages. Firstly, a hierarchical cluster analysis was performed to decide the number of clusters to be retained to the next stage. The Euclidian distance was used as proximity measure in this analysis, since this is the measure most commonly used in data analyses in interval scale (cf. Mooi \& Sarstedt, 2011). 
It was also employed the method of average linkage among clusters as it is not so sensitive to outliers, and because it tends to produce clusters with small intragroup variations (cf. Mooi \& Sarstedt, 2011). The number of clusters to be retained in the next stage was selected based on the analysis of the tree clustering and agglomeration planning matrix resulting from this first stage. The second stage was a cluster analysis through the $\mathrm{k}$-means procedure with the number of clusters defined in the previous stage.

The chi-square tests were performed among the clusters resulting from the cluster analyses, two by two, to each crime computed in the variable of multiplicity of crimes committed.

Four variables were created to the logistic regression analysis: informational reinforcement; utilitarian reinforcement; informational punishment; and, utilitarian punishment.
These variables were computed calculating the mean sum of responses to the items of the questionnaire prepared to assess each of them. To calculate the variable of informational reinforcement, for example, all responses of the same participant were summed for the items elaborated to measure the level of informational reinforcement likely to have been produced by the potential consequences of the delinquent behavior. Then, the result was divided by the number of items that made up that sum. The calculation of these variables only considered the items that achieved $100 \%$ of agreement between judges and the initial table of elaboration of items. These four variables allowed estimating the reinforcement and punishment, informational and utilitarian value that the potential consequences of the delinquent behavior, together, had to the participants according to their own assessments.

\section{RESULTS}

All analyses were performed through the IBM SPSS (Version 22). The variable of multiplicity of crimes committed ranged from 1 to $9(M=3.94 ; S D=2.02)$. A cluster analysis of k-means was performed with the variable, and three clusters had to be retained. The analysis distributed participants in the following three clusters: low multiplicity (LM), mean multiplicity (MM) and high multiplicity (HM). Table 1 shows the descriptive statistics of each group.

Participants belonging to Group LM $(n=48)$ said to have committed 1 to $3(M=1.88 ; S D=0.79)$ different types of crimes. Participants assigned to Group MM $(N=58)$ reported to have committed from 4 to $6(M=4.95$; $S D=$ $0.85)$ types of crime. Participants assigned to Group HM $(N$ =12) reported to have committed from 7 to $9(M=7.33 ; S D$ $=0.65)$ types of crime.

Table 2 shows the results of the 27 chi-square tests performed. To each crime computed in the variable of multiplicity of crimes committed, three tests were performed comparing the clusters two by two: LM vs. MM, LM vs. HM e MM vs. HM. As a general trend, there was a significant association between the level of multiplicity and the commitment of each crime analyzed. It was observed a tendency, as the higher level of multiplicity of the cluster, the higher likelihood of having each crime committed. Probably due to the small size of the sample, the expected frequency of some cells of the contingency table were lower than 5 . This may have resulted in the loss of statistical power, i.e., some tests may have failed in the detection of genuine effects (cf. Field, 2009, p. 692).

The comparison between the LM and MM Groups showed that, based on Cramer's V statistic, the crimes more strongly associated to the low or medium level of multiplicity were drug dealing, $\chi^{2}(1, N=106)=46.08, p$ $<0.001, \mathrm{~V}=0.66$; illegal firearm carrying, $\chi^{2}(1, N=106)$
$=41.84, p<0.001, \mathrm{~V}=0.63$; and criminal conspiracy, $\chi^{2}$ $(1, N=106)=26.66, p<0.001, \mathrm{~V}=0.50$. Considering the odds ratio compared to the participants assigned to the LM Group, those in the MM Group had a 28.7 higher times chance of having reported the practice of drug dealing; 27 times higher of assuming to have committed illegal firearm carrying; and 25 times higher to report to have committed criminal conspiracy. Receiving stolen property/goods was the only crime analyzed that reported no significant association with low or medium level of multiplicity, $\chi^{2}$ (1, $N=106)=0.08, p=0.78$.

Compared to the LM and HM Groups, according to Cramer's V values, the crimes more strongly associated to the low or high level of multiplicity were drug dealing, $\chi^{2}$ $(1, N=60)=41.25, p<0.001, \mathrm{~V}=0.83$; bodily injury, $\chi^{2}(1$, $N=60)=37.60, p<0.001, \mathrm{~V}=0.79$; criminal conspiracy, $\chi^{2}(1, N=60)=32.17, p<0.001, \mathrm{~V}=0.73$; illegal firearm carrying, $\chi^{2}(1, N=60)=17.14, p<0.001, \mathrm{~V}=0.54$; and theft, $\chi^{2}(1, N=60)=16.88, p<0.001, \mathrm{~V}=0.53$. Based on the odds ratio, participants belonging the HM Group had a 125 times higher chance of having declared the commitment of bodily injury; 75 times higher chance of having assumed the involvement in criminal conspiracy; e 19.23 times higher chance of having reported to have committed theft, than the participants assigned to the LM Group. For drug dealing and illegal firearm carrying, the odds ratio assumed values tending to infinite, since all members of the HM Group have committed both crimes. This means that the HM Group participants had much higher chances of reporting the commitment of both crimes than the participants of the LM Group.

The tests performed to compare the MM and HM Groups showed, based on Cramer's V statistics, associations that can be considered as weak to medium regarding the level 
Table 1

Descriptive statistics of the Low, Medium and High Multiplicity Clusters

\begin{tabular}{|c|c|c|c|}
\hline \multirow{2}{*}{ Variable } & \multicolumn{3}{|c|}{ Group } \\
\hline & $\mathbf{L M}$ & MM & HM \\
\hline \multicolumn{4}{|l|}{ Multiplicity } \\
\hline$N(\%)$ & $48(40.7 \%)$ & $58(49.1 \%)$ & $12(10.2 \%)$ \\
\hline Min-Max & $1-3$ & 4-6 & $7-9$ \\
\hline$M(S D)$ & $1.88(0.79)$ & $4.95(0.85)$ & $7.33(0.65)$ \\
\hline \multicolumn{4}{|l|}{ Consequence $M(S D)$} \\
\hline Informational reinforcement & $3.51(0.60)$ & $3.43(0.50)$ & $3.46(0.92)$ \\
\hline Utilitarian reinforcement & $3.52(0.49)$ & $3.58(0.40)$ & $3.53(0.82)$ \\
\hline Informational punishment & $3.98(0.43)$ & $4.00(0.49)$ & $4.04(0.62)$ \\
\hline Utilitarian punishment & $4.18(0.45)$ & $4.05(0.45)$ & $4.18(0.56)$ \\
\hline \multicolumn{4}{|l|}{ Crime $n(\%)$} \\
\hline Bodily injury & $2(4.2 \%)$ & $20(34.5 \%)$ & $10(83.3 \%)$ \\
\hline Homicide / attempted homicide & $21(43.8 \%)$ & $40(69 \%)$ & $11(91.7 \%)$ \\
\hline Receiving of stolen property/goods & $4(8.3 \%)$ & $4(6.9 \%)$ & $5(41.7 \%)$ \\
\hline Theft & $10(20.8 \%)$ & $32(55.2 \%)$ & $10(83.3 \%)$ \\
\hline Robbery & $26(54.2 \%)$ & $49(84.5 \%)$ & $12(100 \%)$ \\
\hline Armed robbery/attemptd armed robbery & $5(10.4 \%)$ & $16(27.6 \%)$ & $7(58.3 \%)$ \\
\hline Drug dealing & $4(8.3 \%)$ & $43(74.1 \%)$ & $12(100 \%)$ \\
\hline Illegal firearm carrying & $16(33.3 \%)$ & $54(93.1 \%)$ & $12(100 \%)$ \\
\hline Criminal conspiracy & $2(4.2 \%)$ & $29(50 \%)$ & $9(75 \%)$ \\
\hline
\end{tabular}

Note. $\mathrm{LM}=$ low multiplicity; $\mathrm{MM}=$ medium multiciplicity; $\mathrm{HM}=$ high multiplicity.

Table 2

Chi-square tests among the Clusters of Different Levels of Multiplicity to each Crime

\begin{tabular}{|c|c|c|c|c|c|c|c|c|c|}
\hline \multirow[b]{2}{*}{ Crimes } & \multicolumn{3}{|c|}{ Chi-square $\mathrm{df}=1$} & \multicolumn{3}{|c|}{ Cramer's V } & \multicolumn{3}{|c|}{$\%$ of cells with $\mathrm{fe}<5$} \\
\hline & $\begin{array}{c}\mathrm{LM} \mathrm{x} \\
\mathrm{MM} \\
N=106\end{array}$ & $\begin{array}{c}\mathrm{LMx} \\
\mathrm{HM} \\
N=60\end{array}$ & $\begin{array}{c}\mathrm{MM} \mathrm{x} \\
\mathrm{HM} \\
N=70\end{array}$ & $\begin{array}{l}\mathrm{LM} x \\
\mathrm{MM}\end{array}$ & $\begin{array}{c}\text { LM x } \\
\text { HM }\end{array}$ & $\begin{array}{c}\mathrm{MM} x \\
\mathrm{HM}\end{array}$ & $\begin{array}{c}\mathrm{LM} x \\
\mathrm{MM}\end{array}$ & $\begin{array}{c}\mathrm{LMx} \\
\mathrm{HM}\end{array}$ & $\begin{array}{c}\mathrm{MM} \mathrm{x} \\
\mathrm{HM}\end{array}$ \\
\hline Bodily injury & $14.68 * * *$ & $37.60 * * *$ & $9.69^{* *}$ & 0.37 & 0.79 & 0.37 & 0 & 25 & 0 \\
\hline Homicide / attempted homicide & $6.84 * *$ & $8.86 * *$ & 2.59 & 0.25 & 0.38 & & 0 & 0 & 25 \\
\hline Receiving stolen property/goods & 0.08 & $8.37 * *$ & $10.73 * *$ & & 0.37 & 0.39 & 50 & 25 & 25 \\
\hline Theft & $12.95 * * *$ & $16.88^{* * *}$ & 3.29 & 0.35 & 0.53 & & 0 & 25 & 25 \\
\hline Robbery & $11.67 * *$ & $8.68 * *$ & 2.14 & 0.33 & 0.38 & & 0 & 25 & 25 \\
\hline $\begin{array}{l}\text { Armed robbery / attempted } \\
\text { armed robbery }\end{array}$ & $4.87 *$ & $13.78 * * *$ & $4.26^{*}$ & 0.21 & 0.48 & 0.25 & 0 & 25 & 25 \\
\hline Drug dealing & $46.08 * * *$ & $41.25 * * *$ & $3.95^{*}$ & 0.66 & 0.83 & 0.24 & 0 & 25 & 25 \\
\hline Illegal firearm carrying & $41.84 * * *$ & $17.14 * * *$ & 0.88 & 0.63 & 0.54 & & 0 & 25 & 50 \\
\hline Criminal conspiracy & $26.66 * * *$ & $32.17 * * *$ & 2.50 & 0.50 & 0.73 & & 0 & 25 & 0 \\
\hline
\end{tabular}

Note. $\mathrm{MB}=$ low multiplicity; $\mathrm{MM}=$ medium multiplicity; $\mathrm{MA}=$ high multiplicity. ${ }^{*} p<0.05 .{ }^{* *} p<0.01 .{ }^{* * *} p<0.001$. 
of multiplicity of committed crimes, if medium or high, with the crimes analyzed. None of the associations found presented an effect size $\mathrm{V} \geq 0.5$. Among the associations with medium effect size, those more strongly associated to the medium or high level of multiplicity were receiving stolen property/good, $\chi^{2}(1, N=70)=10.73, p<0.01, \mathrm{~V}=0.39$; and bodily injury, $\chi^{2}(1, N=70)=9.69, p<0.01, \mathrm{~V}=0.37$. Considering the odds ratio, participants listed in the HM Group had a 10.14 times higher probability of reporting the commitment of the crime of receiving stolen property/good and 9.43 times higher of having reported the commitment of bodily injury than those belonging to the MM Group. The crimes of homicide and/or attempted homicide, $\chi^{2}(1, N=70)$ $=2.59, p=0.11$; theft, $\chi^{2}(1, N=70)=3.29, p=0.07$; robbery, $\chi^{2}(1, N=70)=2.14, p=0.14$; illegal firearm carrying, $\chi^{2}$ $(1, N=70)=0.88, p=0.35$; and criminal conspiracy, $\chi^{2}(1$, $N=70)=2.50, p=0.11$, reported no significant association with the medium or high level of multiplicity.

Two logistic regression analyses were performed. The first one, presented in Table 3, consisted of a multinomial logistic regression, where belonging to the LM, MM and HM Groups was the outcome variable and the informational reinforcement, utilitarian reinforcement, informational punishment and utilitarian punishment variables were predictors. With no missing values recorded, data from all participants were analyzed. No serious violation of linearity in the logit was observed. The insertion of predictors in the model significantly contributed to its predictive value in relation to the constant-only model, $c^{2}(8, N=118)=$ $17.53, p<0.05$. Together, the predictors have significantly distinguished the three different levels of multiplicity of crimes committed. Both the criterion of deviance, $c^{2}(226$, $N=118)=206.07, p=0.83$, and Pearson's, $(226, N=118)$ $=230.65, p=0.40$, indicated that the model fit well to data, since the predicted values did not significantly differ from the expected values. With $=0.16$, a relatively small portion of the variance was explained by the model. The global success rate of the classification predicted by the model was $55.9 \%$, with $47.9 \%$ of participants belonging to the LM Group, $74.1 \%$ of participants assigned to the MM Group, and $0 \%$ of those listed in the HM Group properly classified.

According to Wald's criterion the variables informational reinforcement, $b=0.12, c^{2}(1)=0.07, p=0.80$, and utilitarian reinforcement, $b=0.93, c^{2}(1)=2.30, p=0.13$ did not predict if the participant belonged to the LM or MM Group. That means to say that the report of the level of reinforcement, regardless if informational or utilitarian, of potential consequences of the delinquent behavior did not tend to significantly change the chance of an adolescent or youngster to have committed 1 to 3 types of crime, in relation to the chance of having committed 4 to 6 different types of crimes. The variables informational punishment, $b$ $=1.18, c^{2}(1)=4.00, p<0.05$, and utilitarian punishment, $b=-1.70, c^{2}(1)=6.37, p<0.05$, predicted the belonging to the LM or MM Groups. The 3.27 odds ratio indicates that one additional unit in the scale of description of the level of informational punishment of potential consequences of the delinquent behavior increased in 3.27 times the chance of the participant having committed 4 to 6 different types of crimes in comparison to that of having committed 1 to 3 types of crime. As regards the report of the level of utilitarian punishment, the effect was opposite to that of informational punishment. With a 0.18 odd ratio, one additional unit in the scale of description of the level of utilitarian punishment of potential consequences of the delinquent behavior increased in nearly 5.56 times the chance of the participant having committed 1 to 3 types of crimes in relation to that of having committed from 4 to 6 types of crime.

Table 3

Analysis of Logistic Regression of the Level of Multiplicity of Crimes Committed as a Function of Levels of Reinforcement and Punishment

\begin{tabular}{|c|c|c|c|c|c|}
\hline \multirow[b]{2}{*}{ Variables } & \multirow[b]{2}{*}{ B (SE) } & \multirow[b]{2}{*}{ Wald } & \multicolumn{3}{|c|}{ CI 95\% $(B)$} \\
\hline & & & $\mathbf{L L}$ & $\operatorname{Exp}(B)$ & UL \\
\hline \multicolumn{6}{|c|}{ LM Group vs. MM Group } \\
\hline IR & $0.12(0.48)$ & 0.07 & 0.44 & 1.13 & 2.90 \\
\hline UR & $0.93(0.61)$ & 2.30 & 0.77 & 2.53 & 8.40 \\
\hline IP & $1.18 *(0.59)$ & 4.00 & 1.02 & 3.27 & 10.43 \\
\hline UP & $-1.70 *(0.68)$ & 6.37 & 0.05 & 0.18 & 0.68 \\
\hline (Constant) & $-1.20(2.15)$ & 0.31 & & & \\
\hline \multicolumn{6}{|c|}{ LM Group vs. HM Group } \\
\hline IR & $-0.09(0.82)$ & 0.01 & 0.18 & 0.91 & 4.56 \\
\hline UR & $2.22 *(1.10)$ & 4.10 & 1.07 & 9.16 & 78.31 \\
\hline IP & $1.83 *(0.91)$ & 4.01 & 1.04 & 6.25 & 37.52 \\
\hline UP & $-2.93 * *(1.00)$ & 8.58 & 0.01 & 0.05 & 0.38 \\
\hline (Constant) & $-4.48(3.50)$ & 1.64 & & & \\
\hline
\end{tabular}

Note. $\mathrm{CI}=$ confidence interval; $L L=$ lower limit; $U L=$ upper limit; $\mathrm{LM}=$ low multiplicity; $\mathrm{MM}=$ medium multiplicity; $\mathrm{HM}=$ high multiplicity. $R^{2}=$ 0.14 (Cox \& Snell), 0.16 (Negelkerke). Model $c^{2}(8, N=118)=17.53, p<0.05$. $* p<0.05$. ** $p<0.01$. 
The variable of informational reinforcement, $b=-0.09$, $c^{2}(1)=0.01, p=0.91$ did not significantly changed the chance of the participant to have belonged to the HM Group against the chance of having belonged to the LM Group. The variables utilitarian reinforcement, $b=2.22, c^{2}(1)=$ $4.10, p<0.05$, informational punishment, $b=1.83, c^{2}(1)=$ 4.01, $p<0.05$, and utilitarian punishment, $b=-2.93, c^{2}(1)$ $=8.58, p<0.05$, predicted the belonging to the LM or HM Groups. The 9.16 odds ratio indicates that one additional unit in the scale of description of the level of utilitarian reinforcement of potential consequences of the delinquent behavior increased in 9.16 times the chance of the participant having committed 7 to 9 different types of crimes in relation to that of having committed from 1 to 3 types. In the same sense, one additional unit in the scale of description of the level of informational punishment of potential consequences of the delinquent behavior increased in 6.25 times the chance of the participant having committed 7 to 9 different types of crimes in relation to that of having committed from 1 to 3 types. In the opposite, with a 0.05 odds ratio, one additional unit in the scale of description of the level of utilitarian punishment of potential consequences of the delinquent behavior the chance of the participant having committed 1 to 3 types of crimes increased 20 times in relation to that of having committee from 7 to 9 types.

Finally, a binary logistic regression was performed with belonging to MM and HM Groups as outcome variable and the variables informational reinforcement, utilitarian reinforcement, informational punishment and utilitarian punishment as predictors. The insertion of predictors in the model did not change its predictive value in relation to the constant-only model, $c^{2}(4, N=70)=3.22, p=0.52$.

\section{DISCUSSION}

Based on the application of questionnaires to adolescents and young adults in deprivation from freedom, this study tried to identify potential consequences of the delinquent behavior according to the report of the offenders. The average means higher than 3 to the variables: informational reinforcement, utilitarian reinforcement, informational punishment and utilitarian punishment show that participants, in general, tend to partially or fully agree with the statements presented in the questionnaire. This suggests that access to firearms, drugs and clothing and accessories; establishment of friendships and hostilities; elimination of threats; obtaining goods; pleasant sensations; constant state of stress; involvement with gangs; escape from police; dangerousness; deprivation from freedom; and provision of goods and services to the community and family, tend to bear reinforcement and punishment, informational and utilitarian value to participants. Therefore, the consequences assessed seem to be part of the context in which the respondent adolescents and youngsters are inserted. Once all of them share the practice of criminal behavior, these consequences are likely to constitute potential consequences of the delinquent behavior, which could have been experienced by the respondent offender or by their criminal peers. However, the absence of data on the assessment of non-criminal adolescents impairs any conclusion about the potential causal role played by those consequences.

The chi-square tests showed that, as a rule, the higher the multiplicity of crimes the participants allege to have committed, higher was the likelihood of having reported the commitment of each crime being analyzed. This finding suggests that there is no specific crime or crimes with higher likelihood as the youngster starts committing different crimes. In other words, as it seems there is no unidirectional progression typical to the criminal behavior. Minor crimes, for example, do not necessarily lead to the commitment of violent crimes. Delisi, Angton, Behnken and Kusow, (2015) suggest that thefts, carjacking and related crimes are an overall trend of the criminal behavior and, depending on opportunities and situational factors, may become the starting point towards violence. That is, higher diversity of crimes committed, per se, does not seem to lead to the practice of violent acts, or vice-versa; the commitment of violent crimes does not seem to lead to higher diversity of crimes committed. These data suggest that situational factors and opportunities may have stronger influence on the likelihood of committing violent crimes than the diversity of crimes committed. Longitudinal studies that follow-up the path of the delinquent behavior could evidence possible trends of this kind of behavior, as well as the variables that contribute to the diversification of crimes committed.

Both the chi-square tests and regression analyses showed that: (a) the clusters reporting medium and high level of multiplicity of crimes committed presented much more similarity than differences with each other; and, (b) the cluster with low multiplicity was significantly different from the others. This difference might be related to the commitment of crimes involving delinquent peers or even gangs, such as drug dealing and criminal conspiracy. The likelihood of having both crimes reported did not have significant changes among participants of the MM and HM Groups, but was much higher to participants of these groups than for those of the LM Group. The commitment of those crimes may provide offenders with some degree of protection from their peers also involved in this type of crime. Offenders that do not count on this kind of protection could be more prone to committing more violent crimes, such as homicide, to protect themselves (cf. Adams \& Pizarro, 2013). Having homicide and/or attempted homicide as the second more 
frequent crime among respondents belonging to the LM Group could support this idea, considering that this type of crime is typically motivated by retaliations (cf. SouthamerLoeber \& Loeber, 1988).

The variable informational reinforcement did not predict belonging to the LM, MM or HM Groups. The different types of crime analyzed probably produce similar informational reinforcing consequences. Ackerman (2003) explains that pro-delinquent values generally tend to be shared by groups of criminal adolescents that mutually influence one another, reinforcing the importance of acting according to such values. What is called as values in literature could be understood as a set of informational reinforcement consequences. The access to this type of reinforcement can exist regardless the diversity of crimes committed, merely as a result of falling into the criminal world.

Although the variable utilitarian reinforcement did not predict the belonging to LM or MM Groups, it predicted the belonging to LM or HM Groups. The likelihood of report crimes against property (receiving stolen property/ goods, theft, robbery and armed robbery and/or attempted armed robbery) had no steep increase when the LM Group was compared to the MM Group. Crimes against property can result in the acquisition of stolen or robed objects that could provide the offender with some degree of utilitarian reinforcement. It is possible that the access to this type of reinforcement probably takes place at similar levels in the LM and MM Clusters. However, when the likelihood of the report of crimes against property showed higher increases, what was observed in the comparison between the LM and the HM Groups, the utilitarian reinforcement distinguished these groups. It is recommended that further studies investigate what types of consequences mind more to the report of the level of utilitarian reinforcement of the delinquent behavior. The comparison among groups of offenders engaged and not engaged in crimes that generate income could enable investigating the influence of acquiring goods or money on the report of this level of utilitarian reinforcement.

The higher the value of the variable informational punishment, the higher was the participant's chance of reporting higher levels of multiplicity of crimes committed. Reports of higher levels of informational punishment are likely to indicate that participants have been rejected by family members, neighbors and the community. Parental rejection may lead to delinquent behavior (cf. Jennings, Maldonado-Molina, Piquero, \& Canino, 2010) that, once started, may produce the rejection by peers, and tends to attract other delinquent individuals (cf. Nijhof et al., 2009). The reinforcement provided by criminal peers may be the main source of informational reinforcement of the delinquent behavior. Rejection by family members and the community could enhance the effectiveness of the reinforcement provided by the criminal peers, thus increasing the likelihood of criminal behavior. This increases the likelihood of engaging in other types of crimes, additionally to those already committed. A potential practical implication of this finding lays on the importance of investing in programs based on interventions with the family or communities where the young delinquents live. The implementation of this sort of program could lead to a reduction of informational punishment and, thus, reduce the multiplicity of crimes committed. On this matter, Farrington and Welsh (2003) found that, among the family-centered crime prevention programs, the most effective ones were those that drew on parental behavioral training. Maybe families do not provide young delinquents with reinforcement levels suitable to shape socially desired behaviors.

The variable utilitarian punishment was the only one related to the likelihood of belonging to clusters with lower levels of multiplicity of crimes committed. Intuitively, the main utilitarian consequences of the criminal behavior are those set forth by law, like deprivation from freedom and payment of fines. Assuming that the young respondents are more sensitive to the probability of the sentence than to its magnitude, as suggested by Becker (1968), the fact of having been convicted and being in deprivation of freedom may have significantly increased the reported level of utilitarian punishment of serving a sentence. Higher level of multiplicity of crimes committed are likely to increase the chances of conviction and confinement. Further surveys could compare the report of the level of utilitarian punishment between confined adolescents and those who were never convicted. However, getting data for these last may be not feasible.

The fact that, in the three groups analyzed, the variables informational punishment and utilitarian punishment scored higher than the variables informational reinforcement and utilitarian reinforcement seems to support the idea of asymmetry between reinforcement and punishment regarding its behavioral effects. According to Rasmussen and Newland (2008) in situations of selection, individuals tend to appraise more the punishing than the reinforcing stimuli. In other words, individuals tend to be more sensitive to the adversity ensuing from punishments than to the reinforcement produced by reinforcing stimuli, even when the magnitude of the punishing stimulus is identical to that of the reinforcing one. However, we should consider that even so crimes still happen. In other words, some reinforcements may not even be reported, otherwise no crime would be committed. 
This study faced several limitations from data collection to the performance of analyses. Interviews could not be made with regularity or in proper cozy environments. The gap in the staff of the institutions and imminent risks of rebellions hindered the continuity of interviews and, therefore, obtaining a larger sampling. Moreover, the analyses feasible in this study are restricted to interpreting the verbal behavior rather than the relationships of contingencies effectively observed between the emission of the delinquent behavior and the production of given consequences. In addition, since the instrument used herein was not subjected to a validation process, it had to comprise statements of different levels, ranging from the most generic and comprehensive to those specifically oriented to the offender's context. This could have reduced the accuracy of the measures obtained in this study regarding the levels of reinforcement and punishment, informational and utilitarian, of the potential consequences of the criminal behavior. The comparison of the participants' responses to the questionnaire and those obtained from respondents not engaged in the commitment of crimes could help enlightening the question about to which extent the reinforcing and punishing vale assigned to the consequences assessed ensues from the practice of the delinquent behavior.

Despite these limitations, this study launched a field of investigations about delinquent behavior that considered the informational and utilitarian dimensions of the consequences of this type of behavior, in the perspective of the offenders. The application of the model in the behavioral perspective to other phenomena than consumption shows the theoretical importance of expanding the use of this model to the study of behaviors of choice at large. Exploring the influence of the reinforcement and punishment, informational and utilitarian levels on the delinquent behavior could assist making public policies focused on changing the duty of stimuli that the offender considers relevant. In the light of behavioral economy these changes of duty could increase the cost of crime to the offender, thus reducing criminality. On the other hand, knowing the consequences of the delinquent behavior in the offender's light could contribute to the formulation of more efficient strategies of social inclusion for the offender.

\section{REFERENCES}

Ackerman, J. M. (2003). Delinquents and their friends : The role of peer effects and self-selection. The Pennsylvania State University.

Adams, J. J., \& Pizarro, J. M. (2013). Patterns of specialization and escalation in the criminal careers of gang and non-gang homicide offenders. Criminal Justice and Behavior, 41(2), 237-255.

Asscher, J. J., Wissink, I. B., Deković, M., Prinzie, P., \& Stams, G. J. J. M. (2014). Delinquent behavior, poor relationship quality with parents, and involvement with deviant peers in delinquent and nondelinquent adolescents: Different processes, informant bias, or both? International Journal of Offender Therapy and Comparative Criminology, 58(9), 1001-1019.

Becker, G. S. (1968). Crime and punishment: An economic approach. The Journal of Political Economy, 76(2), 169-217.

Becker, G. S. (1993). Nobel Lecture: The economic way of looking at behavior. Journal of Political Economy, 101(3), 385-409.

Boles, S. M., \& Miotto, K. (2003). Substance abuse and violence: A review of the literature. Aggression and Violent Behavior, $8(2), 155-174$.

Decreto-Lei 2848. (1940, 7 de dezembro). Código Penal [Criminal Code]. Rio de Janeiro, RJ: Presidência da República.

Delisi, M., Angton, A., Behnken, M. P., \& Kusow, A. M. (2015). Do adolescent drug users fare the worst? Onset type, juvenile delinquency, and criminal careers. International Journal of Offender Therapy and Comparative Criminology, 59(2), 180-195.

Farrington, D. P., \& Welsh, B. C. (2003). Family-based prevention of offending: A meta-analysis. Australian and New Zealand Journal of Criminology, 36(2), 127-151.

Field, A. (2009). Logistic regression. In A. Field (Ed.), Discovering statistics using SPSS (and sex and drugs and rock' n'roll) (3rd ed., pp. 264-313). London: Sage.
Foxall, G. R. (1998). Radical behaviorist interpretation: Generating and evaluating an account of consumer behavior. The Behavior Analyst / MABA, 21(2), 321-54.

Foxall, G. R. (2010). Invitation to consumer behavior analysis. Journal of Organizational Behavior Management, 30(2), 92-109.

Gaik, L. P., Abdullah, M. C., Elias, H., \& Uli, J. (2010). Development of antisocial behaviour. Procedia - Social and Behavioral Sciences, 7(2), 383-388.

Günther, H. (2003). Como Elaborar um Questionário (Série: Planejamento de Pesquisa nas Ciências Sociais, No. 1). Brasília, DF: UnB, Laboratório de Psicologia Ambiental. Recuperado de http://www.psi-ambiental.net/ XTextos/01Questionario.pdf

Jennings, W. G., Maldonado-Molina, M. M., Piquero, A. R., \& Canino, G. (2010). Parental suicidality as a risk factor for delinquency among hispanic youth. Journal of Youth and Adolescence, 39(3), 315-325.

Lei 10.826, de 22 de dezembro de 2003 (2003, 22 de dezembro). Dispõe sobre registro, posse e comercialização de armas de fogo e munição, sobre o Sistema Nacional de Armas - Sinarm, define crimes e dá outras providências. Diário Oficial da União, seção 1.

Lei 11.343, de 23 de agosto de 2006 (2006, 23 de agosto). Institui o Sistema Nacional de Políticas Públicas sobre Drogas - Sisnad; prescreve medidas para a prevenção do uso indevido, atenção e reinserção social de usuários e dependentes de drogas; estabelece normas para repressão à produção não autorizada e ao tráfico ilícito de drogas; define crimes e dá outras providências. Diário Oficial da União, seção 1.

Minayo, M. C. de S. (2009). Trabalho de campo: Contexto de observação, interação e descoberta. In M. C. de S. Minayo, S. F. Deslandes, \& R. Gomes (Orgs.), Pesquisa Social: Teoria, método e criatividade (pp. 61-77). Petrópolis, RJ: Vozes. 
Mooi, E., \& Sarstedt, M. (2011). Cluster analysis. In E. Mooi \& M. Sarstedt (Eds.), A Concise guide to market research: The process, data, and methods using IBM SPSS Statistics (pp. 237-284). London: Springer.

Nijhof, K. S., de Kemp, R. A. T., \& Engels, R. C. M. E. (2009). Frequency and seriousness of parental offending and their impact on juvenile offending. Journal of Adolescence, 32(4), 893-908.

Pasquali, L. (1998). Princípios de elaboração de escalas psicológicas. Revista de Psiquiatria Clínica, 25(5), 206-213.
QuickTapSurvey (Versão 5.5.1) [Aplicativo para iPads, iPhones e dispositivos Android]. Toronto, CA: TabbleDabble, Inc.

Rasmussen, E. B., \& Newland, M. C. (2008). Asymmetry of reinforcement and punishment in human choice. Journal of the Experimental Analysis of Behavior, 89(2), 157-67.

Skinner, B. F. (1953). Science and human behavior. New York: MacMillan.

Southamer-Loeber, M., \& Loeber, R. (1988). The use of prediction data in understanding delinquency. Behavioral Sciences \& the Law, 6(3), 333-354. 